\title{
A Retrospective Study on the Benefits of Magical Remedy to Counter Adverse Effects of COVID-19 Infection
}

\author{
J. James, J. Thomas, N. Dileep, and A Viswanath
}

\section{ABSTRACT}

\begin{abstract}
Background: Natural products are the base for modern medicines. Among the natural medicines, honey and turmeric are the unreplaceable natural medicines in Indian culture and worldwide. Even though mono therapy of each is highly beneficial in resolving infections and inflammations, combination therapy will work faster and resolving the medical issues.
\end{abstract}

Objective: The study was conducted during the Coronavirus Disease 2019 (COVID 19) pandemic situation to evaluate the effect of turmeric and honey in treating the symptoms and aftereffects of corona virus infection as most of the people get switched to natural remedies to fight against this situation as there are no exact drugs available for complete cure.

Method: The study was conducted worldwide, and different states were participated in this study. Study was carried with a questionnaire; the questions help to find the knowledge of public about the effects of honey and turmeric and also it explains the way of administration of the mix for those who do not know.

Result: Study was conducted and concluded from the responses of survey questionnaire from 4 different countries. After the completion of the study and on evaluating the responses, the study concluded that most of the people participated in this survey were taking this 'magic remedy mixture' of honey and turmeric on a daily basis for getting immunity and also noticed that most of those who were taking this mix on a regular basis were not affected by the corona virus and few of them get affected but resolved as early as when comparing with those people who were not taking the honey and turmeric mix.

Discussion: The medicinal property of honey has been studied for thousands of years. Antiseptic and antimicrobial properties are the most widely published uses of honey at that time. But now more uses of honey was invented and till now many studies are under progress.

Keywords: Curcumin, corona virus, honey, immunity.
Published Online: August 16, 2021

ISSN: $2736-5476$

DOI 10.24018 / ejclinicmed.2021.2.4.106

J. James*

Department of Pharmaceutics, KVM College of Pharmacy, India.

(e-mail: jishajohn201@ gmail.com)

J. Thomas

Department of Pharmaceutical Chemistry, KVM College of Pharmacy, India.

(e-mail: thomasjohnthomas1 ${ }^{\circledR}$ gmail.com)

N. Dileep

Department of Pharmacy practice, KVM College of Pharmacy, India.

(e-mail: nivedithanidhin ${ }^{@}$ gmail.com)

A. Viswanath

Department of Pharmacy practice, KVM College of Pharmacy, India.

(e-mail: abhijithviswanath8593 @ ${ }^{\circledR}$ gmail.com)

*Corresponding Author

\section{INTRODUCTION}

Building up strong immunity is a time taking process but can boost it by including herbs in your diet. This is very common in many countries for many years. As turmeric and honey are the rich source of immunity, daily consumption will make a huge change in your body. As the world is struggling with the serious adverse effects and aftereffects of corona virus infection, many experts are trying to find a solution. The kitchen ingredient turmeric has antiviral properties due to the presence of natural compound called Curcumin which is best for cure from viruses [1], [2]. Curcumin has an inhibitory effect on Transmissible Gastroenteritis Virus (TGEV) adsorption step and also some inactivation effect which conclude that it has great potential in the prevention of TGEV infection [3]. TGEV is an alpha group corona virus that infect pigs. This Curcumin not only inhibit the action of TGEV, but it also has many effects on other viruses including Dengue virus, Hepatitis B virus and Zika virus. Curcumin also has anti-inflammatory, antitumor activities, healing properties, reduces the risk of cardiovascular diseases, improves digestion, antifungal properties and reduce the risk of Diabetes [4], [5].

During this pandemic, the best gift that everyone can give to their body is healthy foods. Foods can't cure your disease, but it will help your body to fight against the disease and prepare your body stronger than before in a natural way. Apart from turmeric, honey is one among the prime food in immunity booster list. Honey was used to treat nasal congestion, cough and cold. It also has anti-inflammatory 
and anti-bacterial property [6]. Honey contains compounds which can boost your energy, including Vitamin C, Niacin, Calcium, and Iron [7]. While taking honey and turmeric as a combination, the effect will be massive as honey act as a demulcent which will help to soothe the inflamed mucus membrane of the Upper Respiratory Tract Infection (URTI) which is the most common symptom of COVID-19.

We had conducted a survey regarding the effect of honey and turmeric in treating the symptoms, adverse and aftereffects of COVID-19 infection. We found that majority of the population who had a history of taking this immunity boosting mix were tested COVID-19 negative and those who tested positive, recovered as early with fewer symptoms while comparing with those who don't have a history of taking this turmeric and honey mix. From our survey-study, we concluded that we could control the exposure of a deadly pandemic if we make our body strong enough. The immunity boosting drinks are much helpful to fight these conditions.

\section{Methodology}

The study was conducted by accompanying a survey questionnaire. More than 100 people from four different countries were participated in the survey. The survey consists of twelve questions related to the awareness and use of honey and turmeric mix. At the end of collecting the responses of the survey, it's clear that majority of the population is aware about this mix, and they are using it on a daily basis. And one of the major things noticed that those who were taking this mix on a daily basis were COVID negative and a very few of them went under positive but resolved their symptoms as early as while comparing with those who don't take this mix. The study was conducted with hundred people of which $51 \%$ were female and $49 \%$ were male among this the most of them were between the age of 21 to 40 years. Some of the questions included in the survey are mentioned in Table I.

\section{TABLE I: SURVEY QUESTIONNAIRE}

- Have you heard of home remedy by using honey and turmeric powder for treating common cold?

- Have you heard of the magical effect of these combinations to revert the symptoms of Upper Respiratory Tract Infection (URTI) which is common in COVID-19 patients?

- Have you ever used this mix as a preventive measure?

- If used, do you feel relief of symptoms such as runny nose, sneezing, cough etc.?

- If not used, would you like to try this combination?

- Do you ever report as COVID-19 positive?

- If yes, have you used this magical remedy to overcome the symptoms of URTI?

- If no, would you like to try this combination?

In this survey, short information about the administration of the mix were included for getting information to those who were not taking the mix.

To make the mix, take a pinch of pure turmeric powder in a tablespoon and add pure honey about $3 / 4^{\text {th }}$, mix well and consume three times a day at the time of infection and consume once a day as a preventive measure.

\section{RESULT}

The study explains about the medicinal property of honey and turmeric in preventing infections and inflammation and also explains the antioxidant property. As per the survey conducted, many of the participants were from India between the ages of 21 to 40 years. The survey showed that majority of the population are aware about the medicinal use of these combination therapy and many of them are using it daily. The study showed that those who are taking this mix on a daily basis does not get affected by the corona virus as majority of them were tested negative as mentioned in Fig. 1. Some of them were used this mixture previously for improving their immunity as 'immunity booster' during common cold as mentioned in Fig. 2.

\section{DO YOU EVER REPORTED AS COVID 19 POSITIVE \\ 98 responses}

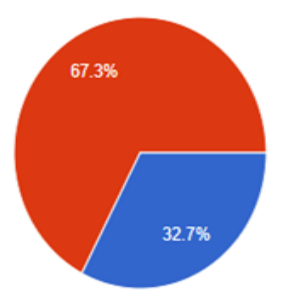

- YES

NO

Fig. 1. Correlation on the usage of magic remedy and its effectiveness from the COVID positive reports.

\section{HAVE YOU EVER USED THESE MIX AS A PREVENTIVE MEASURE}

100 responses
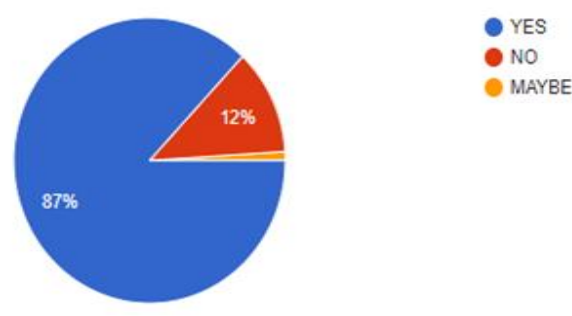

Fig. 2. Correlation on the usage of magic remedy and its effectiveness from the report.

\section{DISCUSSION}

As we have classified the participants based on gender and age. It seems that males and females are taking this drug combination either as a medicine and precaution in almost same pattern as mentioned in Fig. 3. Even then the female respondents are more punctual in this remedy. Age groups in the range of 21 to 50 years are commonly using this medication may be realized the effect of this medicine to cure allergic symptoms like sneezing running nose and the subsequent symptoms. Since this remedy is used for years in common cold even from their childhood, many have their confidence on the effectiveness. Respondents from four different countries have showed that people staying in India particularly from Kerala as mentioned in Fig. 4 are more frequently using this magical remedy may be due to the closeness and availability of these natural materials. About $87 \%$ of the respondents were highly confident and rely on 
this mixture as a remedy to counter the corona virus infection.

GENDER

100 responses

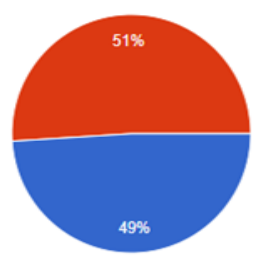

TALE

- prefer not to say

Fig. 3. Gender of the participants.

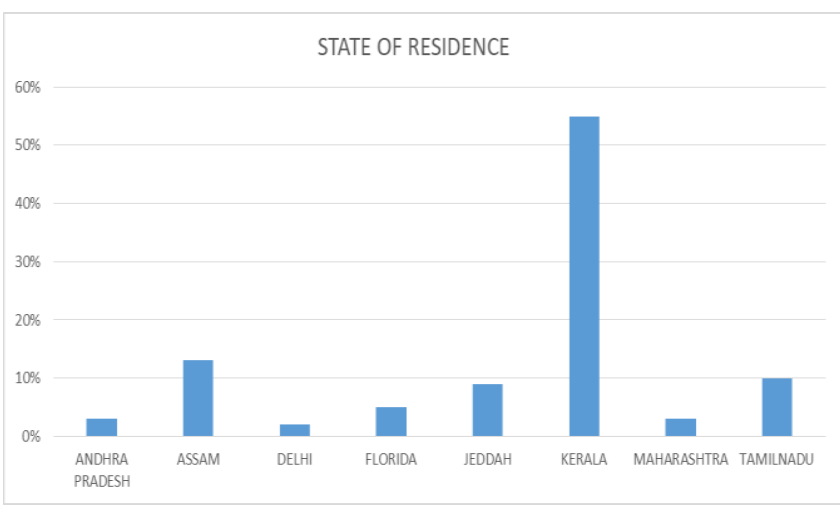

Fig. 4. State where the respondents belong

The medicinal property of honey has been studied for thousands of years [8]. Antiseptic and antimicrobial properties are the most widely published uses of honey at that time [9]. But now more uses of honey was invented and till now many studies are under progress. Ancient documents are the proof of earlier uses of honey in medical purposes, among these some of the ancient documents including 'Smith Papyrus' and 'Ebers Papyrus' are two exceptional examples of honey uses. Many religious books have also written the great values of honey consumption. Studies are reporting that honey have an inhibitory effect on around 60 species of bacteria and some species of viruses and fungi [10], [11]. Honey contains about 200 components, and which is primarily composed of fructose and glucose, also contains flavonoids, phenolic acids, ascorbic acids, tocopherols, catalase, superoxide dismutase, reduced glutathione, Millard reaction products and peptides [12], [13]. Most of these compounds have antioxidant property. Administering honey alone or as adjuvant therapy is a potential natural antioxidant as it is rich in phenolic acids and flavonoids and other antioxidants including glucose oxidase, catalase, ascorbic acid, carotenoid derivatives, organic acids, amino acids, and proteins [14].

Some studies showed the antiviral property of honey by comparing it with acyclovir cream on recurrent attacks of herpes lesions and concluded that topical administration of honey was safe and effective in treating the sign and symptoms of recurrent lesions [15]. Also, studies showed that honey has inhibitory effects on rubella virus activity also honey have anti-inflammatory property as it reduces the activities of cyclooxygenase- 1 and cyclooxygenase- 2 .

Natural products have been used throughout the human history for various purposes [16]. Many of these natural products have pharmacological effects. Almost 4000 years back, turmeric is used in Ayurveda as medicine. Turmeric consists of more than 100 components among that the presence of component named curcuminoids is responsible for the antioxidant property of turmeric [17]. In Ayurveda, turmeric was widely used for treating problems related with digestion and respiratory discomfort like asthma, allergy, and bronchial hyperactivity. The main activities of turmeric in modern medicines include antibacterial, antiviral, antiinflammatory, antitumor, antioxidant and antiseptic [18]. Turmeric are best source of natural antioxidants, thus protects against free radical damage.

It is always better to use combination therapy than single therapy if combination therapy available for treating disease conditions. As honey and turmeric have similar and different medicinal property of their own, thus if we use both honey and turmeric together for treating any medical issues, synergistic reaction takes place and cure may achieve as earlier as the expected period of time.

As no proper medicines are available for treating corona virus, people will decide with what will be comfortable for them. Most of the people from non-medical field in the society are conscious about the potential adverse reactions of modern medicines. So, many of them will try with Ayurvedic products as the primary choice for treatment. Till now many families are following ancient customs and starting their day with water and natural products.

As a part of this study, worldwide surveys were conducted to check the effect of honey and turmeric role in treating the major sign and symptoms of COVID 19. In this survey 100 participants were participated from four different countries. Among this, age between 21 to 40 years are the major participants as mentioned in Fig. 5. The survey showed that most of participants are from India as mentioned in Fig. 6 and many of them are still using this combination when they wake up in the morning as an immunity booster.

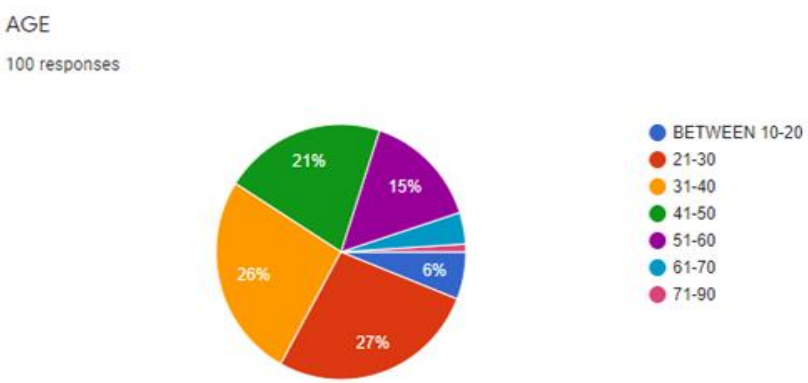

Fig. 5. Age group of the respondents.

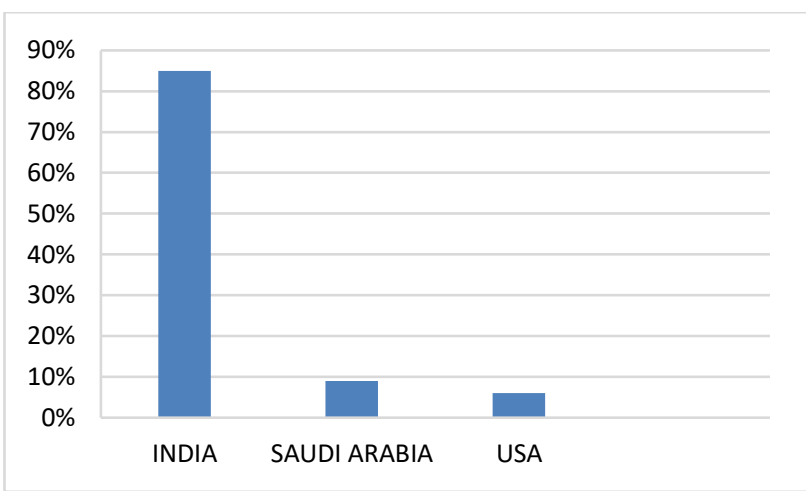

Fig. 6. Country where the respondents belong. 


\section{REFERENCES}

[1] Wright J.S, American Journal of Plant Sciences, "Predicting the antioxidant activity of curcumin and curcuminoids". J MolStruct (Theochem), 591:207-217, 2002.

[2] South E.H, Exon J.H, Hendrix K. Immunopharmacology and Immunotoxicology, "Dietary curcumin enhances antibody response in rats.” ImmunopharmacolImmunotoxicol,19:105-119, 1997.

[3] Ram A, Das M, Ghosh B. "Curcumin Biological and Pharmaceutical Bulletin, attenuates allergen-induced airway hyperresponsiveness in sensitized guinea pigs," Biol Pharm Bull, 26:1021-1024, 2003.

[4] Arora R. B, Kapoor V, Basu N, Jain A. P. Indian Journal of Medical Research, " Anti-inflammatory studies on Curcuma longa (turmeric)," Indian J Med Res, 59:1289-95, 1971.

[5] Gilani A. H, Shah A. J, Ghayur M. N, Majeed K. International Journal of Life Science, "Pharmacological basis for the use of turmeric in gastrointestinal and respiratory disorders," Life Sci, 76:3089-105, 2005.

[6] White J.W. "Composition of honey. In: Crane E," Food and Nutrition Science, Honey: A Comprehensive Survey. London: Heinemann, pp. 157-192, 1979.

[7] Zumla A, Lulat A. Journal of the Royal Society of Medicine, ” Honey: a remedy rediscovered," J R Soc Med, 82:384-385,1989.

[8] Ezz El-Arab A.M, Girgis S.M, Hegazy M.E, Abd El-Khalek A.B, BMC Complementary Medicine and Therapies, "Effect of dietary honey on intestinal microflora and toxicity of mycotoxins in mice," BMC Complement Altern Med, 6:1-13, 2006.

[9] Jeffrey A.E, Echazarreta C.M, Iranian Journal of Basic Medical Sciences, "Medical uses of honey," Rev Biomed, 7:43-49, 1996.

[10] Olaitan P.B, Adeleke E.O, Ola O.I. African Health Sciences, "Honey: a reservoir for microorganisms and an inhibitory agent for microbes," Afr Health Sci, 7:159-165, 2007.

[11] Bansal V, Medhi B, Pandhi P. "Honey -A remedy rediscovered and its therapeutic utility," Kathmandu Univ Med J, 3:305-309, 2005.

[12] Medhi B, Puri A, Upadhyay S, Kaman L. Virtual health library, "Topical application of honey in the treatment of wound healing: a meta-analysis," JK Sci, 10:166-169, 2008.

[13] Sampath Kumar K.P, Bhowmik D, Biswajit C, Chandira M.R. "Medicinal uses and health benefits of Honey: An overview," J Chem Pharm Res, 2:385-395, 2010.

[14] Al-Mamary M, Al-Meeri A, Al-Habori M. Nutrition Research Journal, "Antioxidant activities and total phenolics of different types of honey," Nutr Res, 22:1041-1047, 2002.

[15] Telles S, Puthige R, Visweswaraiah N.K. "An Ayurvedic basis for using honey to treat herpes," Med SciMonit, 13: LE17-17, 2007.

[16] Vane J, Botting R.M. "New insights into the mode of action of antiinflammatory drugs," Inflamm Res, 44:1-10, 1995.

[17] Tilak J, Banerjee M, Mohan H, Devasagayam T.P.A. "Antioxidant availability of turmeric in relation to its medicinal and culinary uses," Phytother Res, 18:798-804, 2004.

[18] Maheshwari R, Singh A.K, Gaddipati J, Srimal R.C. "Multiple biological activities of curcumin: A short review," Life Sci, 78:20812087, 2006.

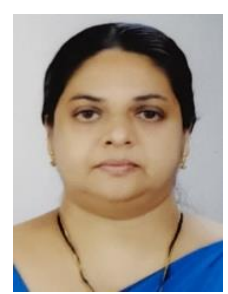

Mrs Jisha James was born in Venmoney Kerala, 25.05.1973. She is pursuing her $\mathrm{PhD}$ in JJTU, Rajasthan, India in 2020 and completed my master's in pharmacy in the field of Pharmaceutics from KM College of Pharmacy, Madurai affiliated to the Tamil Nadu Dr MGR Medical University, Chennai, Tamil Nadu, India in 1999.

She has published articles like:

1. Huntington Disease and Genetical Relation, A Case Study in Kerala, IOSR Journal of Pharmacy, 2020.

2. A high precision phytochemical studies of annonamuricata l. By lcms studies, European journal of pharmaceutical and medical research 2019.

Mrs. James is working as Head and Professor of Department of Pharmaceutics.

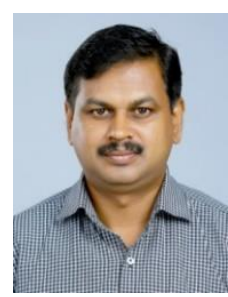

Dr. John Thomas was born in Anikkad, Kerala 19.02.1975. He has completed his $\mathrm{PhD}$ in Pharmaceutical Sciences from Research Development and Innovation Centre (RDIC) C.U. Shah University, Gujarat, India in 2020 and completed his master's in pharmacy in the field of Pharmaceutical Chemistry from JSS College of Pharmacy, Ooty under The Tamil Nadu Dr MGR Medical University, Chennai, Tamil Nadu, India in 1999.

He has published articles like:

1. Huntington Disease and Genetical Relation, A Case Study in Kerala, IOSR Journal of Pharmacy, 2020.

2. A high precision phytochemical studies of annonamuricata l. By lcms studies, European journal of pharmaceutical and medical research 2019.

3. Synthesis of novel clubbed triazolylindeno [1,2-c] isoquinolines as Potent anticancer agents, American Journal of pharmtech research 2017. Dr. Thomas is Academic Director and Professor of Department of Pharmaceutical Chemistry.

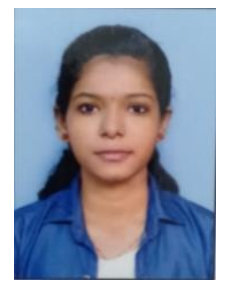

Miss Niveditha Dileep was born inC herthala, Kerala 17.08.1998. She is pursuing her Pharm D at KVM College of Pharmacy (KUHS), Cherthala, India.

She has published articles like:

1. Huntington Disease and Genetical Relation, A Case Study in Kerala, IOSR Journal of Pharmacy, 2020.

2. A case report on Budd Chiari Syndrome which mimics multiple disorders, European Jounal of Clinical Medicine, 2021.

Miss. Dileep is Pharm D student at KVM College of Pharmacy.

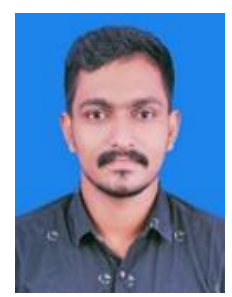

Mr. Abijith V was born in Alappuzha Kerala 21.09.1997. He is pursuing his M.B.A Hospital Management in Bharathiar University Coimbatore and completed his Bachelor of Pharmacy from KVM College of Pharmacy Cherthala, India.

$\mathrm{He}$ is working as Business Development Executive at NatcoPharmapvt ltd India. He has published articles like:

1. Huntington Disease and Genetical Relation, A Case Study in Kerala, IOSR Journal of Pharmacy, 2020.

2. A case report on Budd Chiari Syndrome which mimics multiple disorders, European Jounal of Clinical Medicine, 2021.

$\mathrm{Mr} \mathrm{V}$ is working as Business Development Executive at NatcoPharma. 